\title{
Psychoanalytic contributions to the monitoring of foster families: A literature review
}

\author{
Yasmine Rocha Martins
}

Psychology and Master of Clinical Research Center, Sabará Children Hospital, São Paulo, Brazil

\begin{abstract}
The purpose of this article is to highlight some collaborations that psychoanalytic literature offers for the issue of foster family for children and adolescents. Taking as a starting point the conceptualization of family according to the theories of John Bowlby and Winnicott and their description of the infantile psychism and attachment. Foster family is seen as a qualified alternative to institutionalization, so that psychological monitoring is necessary during this period. Psychoanalysis brings several advances in the area of the reconstruction of the family psyche with the arrival of a new member. We also observe the work of interpreting the individual fantasies of each member of the family about what it means to temporarily foster a child or adolescent and then be able to establish the role and significance of the new family in the life of the recent member and vice versa.
\end{abstract}

Keywords-Foster Family, Psychoanalysis, Child Institutionalization.

\section{INTRODUCTION}

Currently, the children and adolescents living in the city of São Paulo, Brazil who have been removed of their families have the possibility of being allocated in foster families or institutional care.

Foster care provides an improved option instead of institutional care. It is a social protection service, in which families go to multidisciplinary training and monitoring in order to receive children and adolescents removed from their families of origin because of negligence or abuse. And those delivered to social assistance services in maternity hospitals.

The biological parents of these children have their family power deprived in most cases because abandonment or social risk, consequently guardianship is given to the public power represented by the Child and Youth Courts, who refer the children to the registered family or institutional care service in the city. Family care programs is chosen for those children who are most likely to reintegrate into their original family, according to Law No. 12,010 of August 3, 2009. ${ }^{1}$

The National Council for Social Assistance in conjunction with the National Council for the Rights of Children and Adolescents, developed the main objectives of the reception service. ${ }^{2}$

In general, it was decided that the technical team is responsible for providing assistance to the foster families, the family of origin, and the children. Focusing on strengthening the healthy bond between those involved in the process.
Also according to Law No. 12,010, of August 3, 2009 , institutional reception should not extend for more than two years, unless there is the necessity, duly substantiated by the judicial authority.

In article 19, item III of the same law, is described that the reintegration for biological family will have preference in relation to any other measure, being understood by family the parents and the extended family, those besides the parents and children unit, formed by relatives close to which the child or adolescent already has an affective bond and affinity.

In article 34, item I of the same law, is detailed that the family care program will have preference over institutional care, in view of the temporary and exceptional character of the measure.

The Municipal Secretary of Assistance and Social Development is responsible for the administration of the vacancies available in the types of reception described above. According to the criteria pre-established by a special committee, requests to receive the children are studied case-by-case. Only after individual analysis the child is allocated in institutional care or family care.

According to the National Plan for the Protection, Promotion and Defense of the Rights of Children and Adolescents, families that intend to enter the family care program need to meet some prerequisites, such as: flexibility, motivation, emotional availability, healthy standard of care, attachment and detachment relationships and emotional stability. ${ }^{3}$

The child is not an independent organism, their survival is linked to the satisfaction of basic needs such as 
shelter, food and protection, as well as their emotional needs, such as living in an atmosphere of affection, strengthened bonds and security. ${ }^{4}$

The attachment behavior is a way for the child to approach another individual better able to deal with the world. It is common for this attachment relationship to happen between mother and child, bringing a sense of security and enabling the child to explore the outside world. ${ }^{5}$

The child internalizes a standard of security, in the sense that if the outside world causes him or her some kind of suffering he or she will have someone to comfort or encourage if there is a threat. Around the age of three, the consequence of the attachment relationship is building a feeling of trust in yourself and those around you.

Affection is extremely important in the motherchild relationship. The mother's mature personality is already structured and provides her baby with support and a favorable climate for development. The mother figure is one that represents the environment and mediates the stimuli of the external world and the baby. ${ }^{6}$

The construction of the affective bond in the foster family requires dedication and reciprocal emotional availability among all involved. The construction and permanence of satisfactory affective relationships is linked to vital function. In other words, the healthy experience of the human being is intrinsically connected to good family relationships and a welcoming environment. ${ }^{7}$

A welcoming environment and nurturing good family relationships can be experienced by substitute bonds, not just biological ones. Being a mother has no direct and unique relationship with biological ties, it is related to a feeling of comfort, security, care and affection. ${ }^{8}$

Children who are in foster care seek in foster mothers what they did not obtain from their biological mothers. It is common for foster children to have a history of physical or emotional neglect or inefficient attachment relationship. ${ }^{7,8}$

Foster parents undergo extensive training and follow-up before receiving foster children. Emotionally it is common for moments of anxiety to anticipate the child's arrival. When it comes time to approach, the child or adolescent, demands love and attention, which contributes to the formation of the affective bond between everyone.

So that, in view of the affective demands that the infant himself/herself presents, the foster mothers and fathers dedicate themselves to the same extent as that required by the children foster.

\section{PSYCHOANALYTIC ANALYZE}

The family and couple clinic emerged as an extension of individual care, based on the texts of Freud, Bleger, Pichon-Riviere, Winnicott, Klein and Bion theorized, that the members of the family group, either substitute or biological, present a collective unconscious mechanism, which guide actions and attitudes. ${ }^{9}$

Puget based on his doubts and concerns in clinical practice, realized that the simple displacement of individual analysis would not meet the requirements of family bonds. ${ }^{10}$

Gomes and Levy wrote about groupality, which is a determined sharing of rules in carrying out any activity together. they also developed the expansion of the transfer in order to designate the one that occurs between family members. ${ }^{9}$

Freud started the study of the transferential phenomenon as a way of resisting psychoanalytic care only. Later he recognized the phenomenon in the analytical relationship, recognizing it as a reissue of past psychic traumas. In the individual and traditional setting, the transference is directed only to the therapist, while in group contexts it takes on a different attribute. ${ }^{11}$

The transference phenomenon becomes expanded and multilateral, as it comprises the relationship with the therapist and the members themselves. Its meaning is also crossed because it takes into account a divergence of experiences of meaning, that is, it is associated with previous events and repressions. ${ }^{11}$

The therapist who takes care of the foster families, must handle the transfers presented by the family members and deal with their own countertransference towards this group. Like Winnicott who argued about the mother being good enough to tolerate certain negative behaviors of the child, the therapist must tolerate the negative transference feelings of his patients and then interpret them. ${ }^{12}$

Psychoanalytic therapy works beneficially in the construction of a sensitivity in foster parents towards their adopted child. The sensitivity is also known as tuning, the ability to read the subtle and often non-verbal signals of the minor. ${ }^{13}$

So that the ability to trust yourself and people around you are built. Sensitivity can be improved through intervention. As a two-way street, it can be described about the analyst's sensitivity as the one that operates the analyst's subjectivation process, that is, it develops small perceptions that come in the atmosphere of the analysis, since this, the sensitivity provides the countertransference and thus provides the leading pair of the analysis to act. 
The role of the psychoanalyst in social assistance, raised the premise that it is through listening that the subject empowers himself of his essence and power. ${ }^{14}$

Psychoanalysis, therefore, creates a space for listening to the subject's history and possible anguish, consequently producing narratives about the evil or wellbeing of experiencing an unprecedented situation.

In other words, in the face of the demands of foster families, psychoanalysis provides a clinical device for social assistance, because those treated within the foster program for foster families did not seek psychoanalytic care, but had a link with an assistance institution.

There is an intervention on which the subject's real demand would be the foster mother or father in the face of psychoanalytic care. Based on the questions raised by them, it is that psychoanalysis can assist in the promotion of consciousness, through a better understanding of your unconscious and patterns of emotions.

Such qualified self-knowledge helps foster parents to better deal with the demands exposed by the child or adolescent, so that, when dealing with their own demands, living with others gains a curative functionality.

Family coexistence is a right for everyone, so, foster families help in the possibility of the minor having family experience, being deprived of his family of origin.

Family is as an extension of the individual, in this case, the family therapist, would be the one who causes and emerges conflicting questions and possible family secrets, which would not otherwise be revealed. ${ }^{15}$

About the technique for serving families, conceptualized inter-fascination that would be the meeting point for the individual ghosts of each family member. A transitional space of exchange is created, in which antecedent stories about each one and the ancestors and their unfolding in the family routine emerge. ${ }^{16}$

In practice, this concept indicates that the family becomes a unit when there is a problem, based on collective and individual anxieties that are structured and the family life cycle develops.

Each family has its particularity and from the creation of its specific problem, ways of dealing with each other are created. It is from living together at home that one learns to deal with one's own perceptions about the environment and the perceptions of the external world.

Family refers to intimate configurations that contribute to the feeling of belonging, of roles in the world, of rules to be followed or broken. In summary, family is related to behavior patterns and influences on how to communicate and solve problems. ${ }^{16}$
The family group is increasingly integrated with narcissistic and libidinal investments, a fact very common in family dynamics. The narcissistic investment is where there is an identification of the ego with an idealized internal objective, that is, in the family sphere there is a collective self-investment. ${ }^{17} \quad$ Thus, when structuring the narcissistic bond each member of the family is the psychological support of the other, all contributing to the strengthening of the group. Libidinal investment, on the other hand, is that directed towards objects, no longer myself, in this way the positions and functions of its members are created within the family psychism. Such investment provides the unconscious sharing of being together and organizes the functioning of the family group as a unit.

Foster family reflects a context of previous destructuring, rupture, distancing and changes. However, it is an experience that provides the opportunity to build new family bases, represents the chance to reframe and include one more member in the form of psychic investment as explained above. ${ }^{18}$

The foster family is also a space for interaction with exchanges, activities that used to be commonplace such as lunch or a walk in the park take on new colorful shapes for the foster family.

Each new family activity makes the bond stronger and stronger. Daily affective exchanges express loving reciprocity between foster parents and foster children.

When you feel loved, sharing and assuming responsibilities with other people is a good enough environment to live, a psychically healthy adult develops.

The formation of a subject does not occur by itself, the environment where he was inserted has a function of reliable care where someone perceives the needs of the children and provides receptivity in a sufficiently good way, in which the child can create emotionally a personal world to live. ${ }^{19}$

These impressions are marked in the child's unconscious and make him a citizen capable of specific skills to live. The mother or her substitute when showing affection protects the infant's ego and allows the construction of an integral personality and with a pattern of existential continuity. ${ }^{19}$

\section{CONCLUSION}

As a child or adolescent inserted in the foster family feels in a warm and comfortable environment, developed or improved their ability to share in others and in themselves. The reciprocal affectivity moves away like fantasies of neglect, abuse and violence. The tools to improve traumas are dedication, convenience, attention and affection. 
The foster mother and father assist in the construction of a new reality, provide emotional support, and prepare the child for further separation. It is like a moment of mutual learning.

That's because foster parents gain a lot with the experience of foster a child and adolescent for a period. They have the opportunity to develop their empathy and bonds, since they know from the beginning that the child will be with them only for a certain period.

The emotional bond built between everyone involved does not break, even when the child leaves. Memories and learning remain active in everyone's mind. It is a relationship of mutual gratitude.

The relationship with the foster family does not replace the relationship with the biological family. The construction of the bond with the biological family is emotionally influenced all the time.

The family psychoanalytic helps in the elaboration of the individual suffering of the members in building a new family, it also helps in the restructuring of expectations regarding the new and in the construction of future plans.

From the point of view of the child or adolescent, psychoanalytic support helps in the insertion of the new family environment, in affective exchanges and child symbolization. The foster family is a temporary environment, but it can collaborate in a healthy way for the child development.

\section{REFERENCES}

[1] Brazil. (1988). Constitution of the Federative Republic of Brazil. October 1988. Law N¹2.010, of August 3, 2009.

[2] Brazil. (2009). National Council for Social Assistance and National Council for the Rights of Children and Adolescents. Technical guidelines: childcare services for children and adolescents.

[3] Brazil. (2013) National Council for Social Assistance and National Council for the Rights of Children and Adolescents. National plan to promote, protect and defend the right of children and adolescents to family and community life. Brasilia. DF

[4] Bowlby, J. (1988). Maternal Care and Mental Health. Porto Alegre: Medical Arts.

[5] Bowlby, J. (1989). A Safe Base: clinical applications of attachment theory. Porto Alegre: Medical Arts.

[6] Spitz, R. A. (1979). The first year of life: a psychoanalytic study of the normal and anomalous development of object relations. São Paulo SP, Martins Fontes.

[7] Cabral, C. (2004) Perspectives on family care in Brazil. In: C. Cabral (organizer), Family care: experiences and perspectives. Rio de Janeiro: RJ: Land of Men.

[8] Cavalcante C. M. \& Jorge M. S. B. (2008) Mother is the one who creates: the meaning of a substitute motherhood Psychology studies, 25 (2), 265-275. Retrieved from
https://www.scielo.br/scielo.php?script=sci_arttext\&pid=S0 103-166X2008000200011

[9] Gomes, I. C., \& Levy, L. (2009). Family and couple psychoanalysis: main theoretical references and Brazilian perspectives. Aletheia, (29), 151-160. Retrieved from http://pepsic.bvsalud.org/scielo.php?script=sci arttext\&pid= S1413-03942009000100013\&lng=en\&tlng=en

[10] Puget, J. (1997) The couple: a psychoanalytic entity. In: Zimerman, D.E. et al. How we work with groups. Porto Alegre: Artmed, p. 283-292.

[11] Freud, S. (1912) The dynamics of transference. Complete Works. Rio de Janeiro: Imago, p. 129-143. (Standard Brazilian Edition, Vol. XII)

[12] Winnicott, D. W. (1947) Hate in countertransference. In: From pediatrics to psychoanalysis: chosen works. Rio de Janeiro: Imago, 2000. p. 277-287.

[13] Júnior, A. M. \& Martin, C. A. (2014). For a psychoanalysis to come. Psychoanalytical time, 46 (2), 381-385. Retrieved from:http://pepsic.bvsalud.org/scielo.php?script=sci_arttext \&pid $=$ S0101-48382014000200013

[14] Scarparo, M. L. D. \& Poli, M. C. (2008). Psychoanalysis and Social Assistance. Barborói, 28 (2), 50-74. Retrieved from http://pepsic.bvsalud.org/pdf/analytica/v4n6/09.pdf

[15] Ackerman, N.W (1969). Neurotic family psychotherapy. Buenos Aires: Paidos

[16] Eiguer A. (1985). A family on the couch. Porto Alegre: Medical Arts.

[17] Klein, M. (1945) "The Oedipus complex in the light of archaic anxieties", p.413-464. (1921-1945). Volume I of the complete works of Melanie Klein. Rio de Janeiro: Imago.

[18] Delgado, P. (2010). The experience of bonding and family care: reflections, myths and challenges. Themes in Psychology, 18 (2), 457-467. Retrieved from http://pepsic.bvsalud.org/scielo.php?script=sci_arttext\&pid= S1413-389X2010000200019

[19] Winnicott, D. W. (1975). The child and his world. Rio de Janeiro: Zahar. (Original work published in 1964; respecting Hjulmand's classification we have 1964a) 